\title{
EVALUATING ACOMP, FLAASH AND QUAC ON WORLDVIEW-3 FOR SATELLITE DERIVED BATHYMETRY (SDB) IN SHALLOW WATER
}

\author{
Abdul BASITH $\mathbb{1}^{*}$, Ratna PRASTYANI® \\ Department of Geodetic Engineering, Universitas Gadjah Mada, Yogyakarta, Indonesia
}

Received 28 October 2019; accepted 15 September 2020

\begin{abstract}
Bathymetry map is instrumental for monitoring marine ecosystem and supporting marine transportation. Optical satellite imagery has been widely utilised as an alternative method to derive bathymetry map in shallow water. Nonetheless, interactions between electromagnetic energy and Earth's atmosphere causing the atmosphere effects pose a significant challenge in satellite-derived bathymetry (SDB) application. In this study, Worldview-3 imagery was used to obtain bathymetry map in shallow water. Three atmospheric correction models (ACOMP, FLAASH and QUAC) were employed to eliminate atmospheric effects on Worldview-3 imagery. Three simple band ratios involving coastal blue, blue, green and yellow band were used to test the performance of atmospheric correction models. ACOMP combined with blue and green band ratio efficaciously provided the best performance where it explained $77 \%$ of model values. Bathymetry map obtained from Worldview-3 was also validated using bathymetry data acquired from bathymetric survey over the study area. The estimated depths shared aggregable results with measured depths (depth $<20 \mathrm{~m}$ ) with accuracy of $2.07 \mathrm{~m}$. This study shows that robust atmospheric correction combined with suitable simple band combinations offered bathymetry map retrieval with relatively high accuracy.
\end{abstract}

Keywords: bathymetry, SDB, Worldview-3, ACOMP, FLAASH.

\section{Introduction}

Bathymetry is essentially information about depth and underwater topography of many different types of waterbody such as ocean, river and lake. Bathymetry map is increasingly important as scientists study more about aquatic ecosystem such as for benthic habitat mapping, detecting the movement of sediment and for monitoring water quality especially in coastal waters (Eugenio et al., 2017; Giardino et al., 2019; Shi et al., 2018). Bathymetry map is also instrumental in engineering application such as for supporting marine infrastructure designs and providing safety guidelines for marine transportations (Mavraeidopoulos et al., 2018). Given the example of bathymetry map in biology and engineering application, the use of bathymetry map also stretches out to administration of marine resources in marine's policy application (Hell et al., 2012). Clearly, bathymetry map plays critical role in many different fields, thus there is a pressing need for accurate depth retrieval.

Bathymetry map can be obtained by conducting conventional bathymetric survey or by utilising remote sensing data. Optical satellite imagery has been widely used as an alternative approach for depth retrieval, especially in areas where conventional bathymetric survey is difficult to be conducted. Depth retrieval using satellite imagery provides many advantages such as time and cost efficiency when compared to conventional bathymetric surveys. Depth retrieval, often called as satellite-derived bathymetry (SDB), using optical satellite imagery relies on the principle of visible light penetration in water (Jawak et al., 2015). In visible spectrum, blue and green light are able to penetrate into water column. However, depth retrieval using optical imagery is a complex process which has to take several factors into account such as water properties, bottom signals and atmospheric effects (Hernandez \& Armstrong, 2016).

Atmospheric effect has become a major challenge in digital image processing as it degrades the radiometric quality of satellite image and leads to erroneous analysis. Several atmospheric correction models have been implemented to eliminate the atmospheric effects and to improve the quality satellite imagery. Broadly, those atmospheric correction models can be divided into three categories which are radiative transfer model, imagebased relative model and empirically statistical model.

*Corresponding author. E-mail: abd_basith@ugm.ac.id 
Among the three categories, radiative transfer model offers better performance and higher accuracy since it requires prior knowledge of real-time of atmospheric parameters and accurate sensor characteristics. There are many different algorithms using radiative transfer model such as Second Simulation of The Satellite Signal in The Solar Spectrum (6S), Fast Line-of-sight Atmospheric Analysis of Spectral Hypercubes (FLAASH) and Airborne Atmospheric and Topographic Correction (ATCOR) (Cooley et al., 2002; Kotchenova \& Vermote, 2007; Richter \& Schläpfer, 2002). On the contrary, image-based relative model is less complex in which the atmospheric effects are eliminated based on image characteristics, such as by performing Quick Atmospheric Correction (QUAC) algorithm (Bernstein et al., 2012a). Lastly, empirical statistical model is performed according to statistical relationship (e.g. linear) between remote sensing reflectance with reflectance recorded on image (Liang et al., 2012).

Once the radiometric quality of an image is improved by performing atmospheric corrections, there are several methods which can be employed to derive bathymetry from optical imagery. An extensive number of studies have been documented in proposing methods for depth retrieval. The most well-known method is the empirical Lyzenga (1981) method in which reflectance is function of water depth, water optical properties and bottom albedo. With the assumption of uniformity of water properties in given area of image scene, depth is estimated based on log-linear function with image reflectance. The log-linear function can be employed using single or multiple spectral bands. On the other hand, Stumpf et al. (2003) developed an approach for depth retrieval by using the ratio of two spectral bands (green and blue). Owing to the theory that light attenuation in water is wavelength dependent, the ratio of reflectance is a function of water depth and significantly less sensitive to bottom albedo.

With the advances of Earth observation satellite, highresolution multispectral satellite imagery has made major contribution for bathymetry mapping. Many researches have utilised high-resolution multispectral satellite imageries for deriving bathymetry such as IKONOS (Lyzenga et al., 2006; Mishra et al., 2007), Pleiades (Said et al., 2017), Worldview 2/3 (Hernandez \& Armstrong, 2016; Parente \& Pepe, 2018) and SPOT 6/7 (Sánchez-Carnero et al., 2014). Worldview-2/3 in particular seems to be more appealing than the other high-resolution multispectral satellite imageries thanks to the newly added spectral bands is.e. coastal blue, yellow and red-edge bands. Furthermore, Worldview-3 is also equipped with CAVIS sensor which measure the atmospheric parameters required for atmospheric correction of Worldview-3 imagery. By using CAVIS data, Digital Globe provides atmospherically compensated (AComp) product. Considering this tremendous opportunity, this paper presents an evaluation of AComp, FLAASH and QUAC atmospheric models for deriving bathymetry in shallow water of Karimun Island. The result of SDB is also validated using in-situ depth data acquired from conventional bathymetric survey using single beam echosounder.

\section{Materials}

\subsection{Study area}

Karimunjawa archipelago comprises 27 islands in Java sea with many different ecosystems such as coral reef, seagrass, mangrove, and low land tropical rainforest (see Figure 1). Karimun is the biggest island with land area of 2700 ha and located approximately $125 \mathrm{~km}$ north of dense-populated Java island. In this present work,
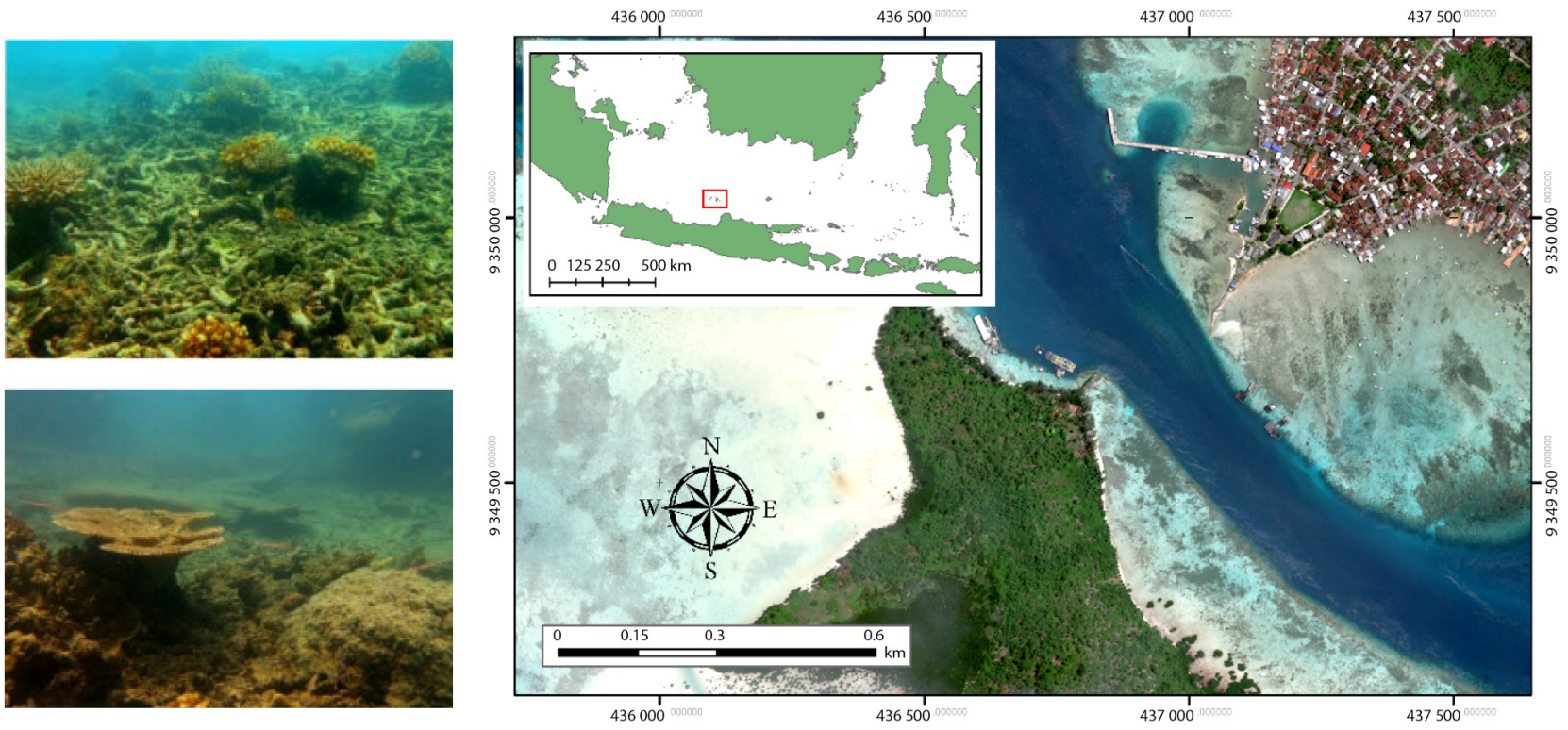

Figure 1. Study area for bathymetry retrieval in Karimun water with extensive area of coral reef (left, source: http://kkji.kp3k.kkp.go.id) 
Karimun water was chosen as representative area of shallow water. Karimun is protected area which includes extensive area of fringing and patchy coral reefs surrounding the island.

\subsection{Satellite data}

In this present work, Worldview-3 was used to derive bathymetry in Karimun shallow waters. The image was recorded on 21 February 2018. The Wolrdview-3 data consist of two main products which are atmospherically compensated (AComp) and uncompensated image. Both products have been geometrically corrected or orthorectified (OR2A). Thus, there was no need for further geometric image processing. The products comprised panchromatic and multispectral image with spatial resolution of $0.31 \mathrm{~m}$ and $1.24 \mathrm{~m}$ respectively. Figure 2 depicts the spectrum of Worldview-3's spectral bands.

As illustrated in Figure 2, Wolrdview-3 sensor is able to perform imaging in coastal blue, yellow and red-edge bands in addition to the common blue, green and red band. The availability of coastal blue and blue band enhances bathymetry study due to their strong water penetration capabilities. Coastal blue is characterised as energy spectrum with the least absorption by water and less affected by atmospheric scattering (Digital Globe, 2010). At the longer wavelength, yellow band is also considered as a new channel and crucial for feature classification both on land and in water. Yellow band has been reported as an effective channel for deriving bathymetry (Nuha, 2019). On the other hand, red-edge band is also newly added which has been introduced in previous Worldview-2 mission. Red-edge band is powerful for monitoring chlorophyll-A concentration in coastal and inland waters (Delegido et al., 2011; Vanhellemont \& Ruddick, 2016). Not only Worldview-3’s

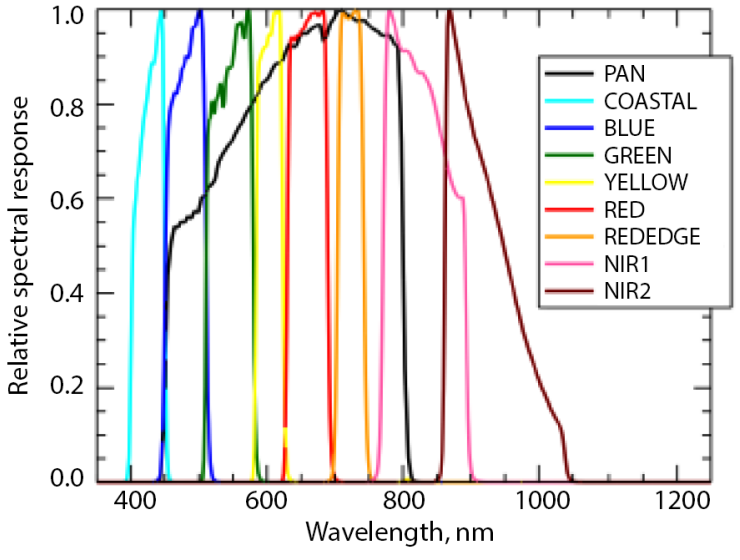

Figure 2. Worldview-3 spectral radiance response for the visible and near-infrared (VNIR) bands (source: http://worldview3.digitalglobe.com/)

spectral resolution, but its spatial resolution also plays a critical role in marine studies with its unprecedented details.

\subsection{Bathymetric survey}

Bathymetric survey was conducted in Karimun water on 21 and 22 March 2019. The survey was carried out using Bathy-2010 SyQwest Single Beam Echosounder to measure the depth of seafloor $(z)$ as illustrated in Figure 3. The planimetric position of depth $(\mathrm{x}, \mathrm{y})$ was recorded using Trimble NET R9 Geodetic GNSS Receiver. Furthermore, tidal data in Karimun waters was acquired from measurement using Valeport Tidemaster which was deployed on the coastal jetty. Tidal data were used to correct measured depth based on the vertical datum. Data acquired from this bathymetric survey were processed in order to obtain depth points with its planimetric position.
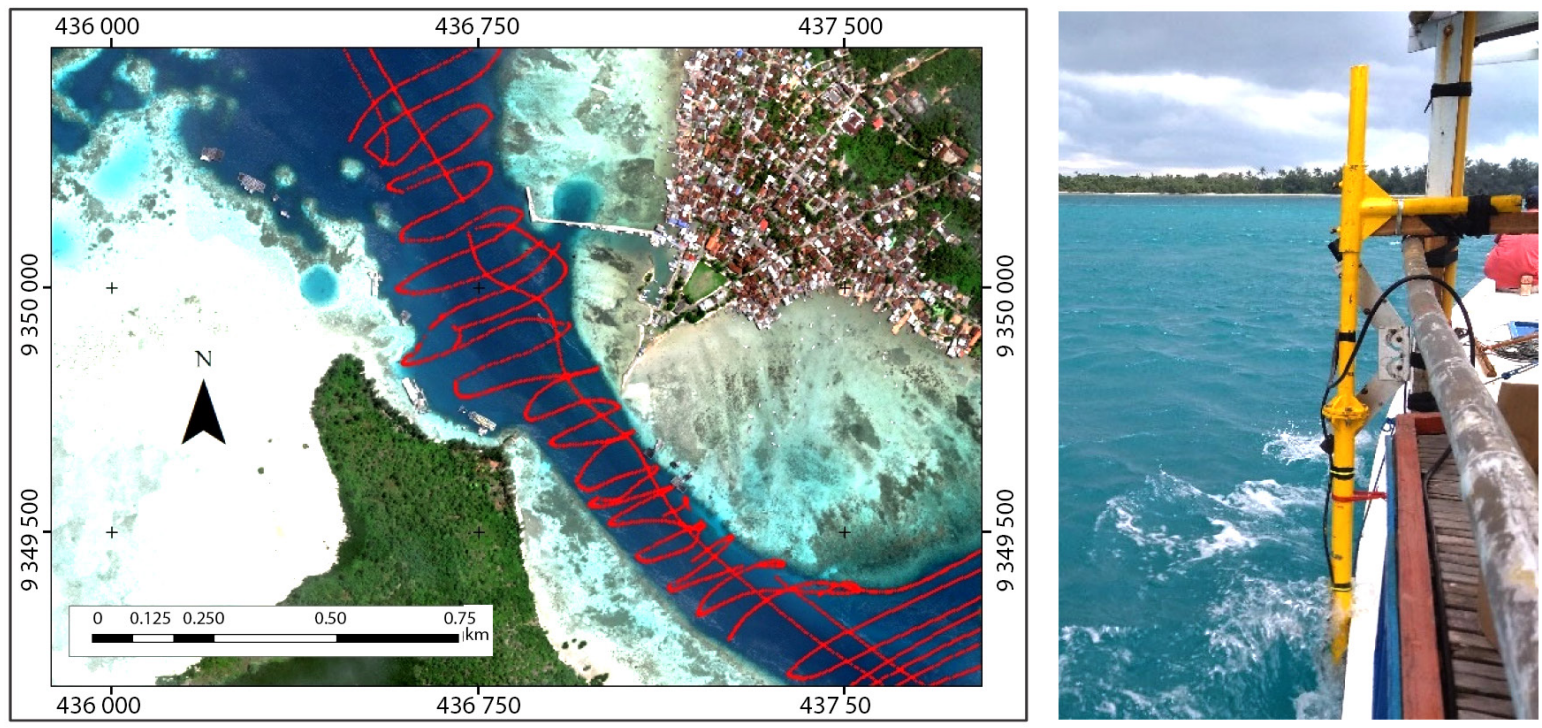

Figure 3. In-situ bathymetric points (left, represented in red) in the study area 


\section{Methods}

\subsection{Atmospheric correction models}

Atmospheric correction is crucial in image pre-processing. It is aimed to eliminate atmospheric effects in order to obtain high-quality reflectance of objects on the imagery. Multispectral of ocean remote sensing in particular faces a peculiar challenge when it comes to removing atmospheric effects due to complex interactions between electromagnetic energy emitted from the sun, atmosphere (i.e. scattering and absorption) and water properties (i.e. chlorophyll-A, total suspended material and dissolved organic matter) (Ilori et al., 2019). To overcome this problem, two atmospheric correction models (FLAASH and QUAC) were applied to Worldview-3 imagery to be further compared with AComp product provided by Digital Globe. Those three atmospheric correction models were then tested in order to evaluate their performances for bathymetry retrieval.

\section{AComp}

As one of the most leading company which provides high-resolution multispectral imagery, Digital Globe expands its product offerings by providing atmospherically corrected imagery which is generated by its proprietary atmospheric correction model called AComp. In eliminating atmospheric effects on Worldview-3 imagery, Digital Globe uses atmospheric parameters measured by CAVIS sensor with $30 \mathrm{~m}$ spatial resolution. The product is delivered in 11-bit radiometric resolution. Rescaling was performed to obtain surface reflectance that ranges from 0 to 1 .

\section{FLAASH}

FLAASH is atmospheric correction model based on MODerate resolution atmospheric TRANsmission (MODTRAN-4) radiative transfer code. The principle of FLAASH can be mathematically expressed as follows (Cooley et al., 2002):

$$
L_{T O A}=\left(\frac{A \rho_{S U P}}{1-\rho_{e} S}\right)+\left(\frac{B \rho_{e}}{1-\rho_{e} S}\right)+L_{0},
$$

where $L_{T O A}$ is Top-of-Atmosphere reflectance, $\rho_{S U P}$ is surface reflectance in individual pixel, $\rho_{e}$ is averaged surface reflectance from the surrounding region, $S$ is the spherical albedo of atmosphere, $L_{0}$ is radiance and $A$ and $B$ are coefficient depending on the atmospheric and geometric conditions.

In the processing, users are required to input several parameters manually which includes image characteristics and atmospheric parameters at satellite passing time. Image scene characteristics were obtained from image metadata. In addition, Indonesian National Digital Elevation Model (DEMNAS) was used to obtain average ground elevation over the study area. Atmospheric and aerosol model were set to Tropical and Maritime, whereas water vapour was estimated about $4.11 \mathrm{~g} / \mathrm{cm}^{2}$ in the tropics and was set accordingly in Water Column Multiplier (Harris Geospatial, 2009). In this case, water retrieval was not performed due to the absence of channel with wavelength at $1135 \mathrm{~nm}$. Also, aerosol retrieval was set to none due to the absence of upper channel at wavelength of $2100-2250 \mathrm{~nm}$.

\section{QUAC}

Unlike FLAASH, QUAC is image-based atmospheric correction which does not require any atmospheric parameters as inputs. It only requires approximate specifications of channels' central wavelength and their radiometric calibration. It also works much faster than the physicsbased atmospheric model (Bernstein et al., 2012b). Furthermore, QUAC retrieves surface reflectance within the image based on offset and gain parameter which can be expressed as follows:

$$
\rho_{S U P}=\operatorname{gain}\left(L_{T O A}-\text { offset }\right)
$$

where offset is the lowest reflectance of each channel and gain is the ratio between the averaged endmember spectra representing a reference library of material reflectance spectra. Note, QUAC does not take varying atmospheric condition within the image scene into account.

\subsection{Land masking}

After the atmospheric correction, land masking was done in order to mask out the land and ensure that the pixels processed for depth retrieval are water. Land masking was performed based on Normalised Difference Water Index (NDWI). NDWI is useful for delineating water features by making use near-infrared (NIR) and green region to separate waters from the presence of soil and terrestrial vegetation features (McFeeters, 1996). However, Parente and Pepe (2018) replaced green with coastal blue band in order to mask out the land for deriving bathymetry using Worldview-3 imagery. Hence, NDWI is calculated as follows:

$$
\text { NDWI }=\frac{\text { Costalblue }- \text { NIR2 }}{\text { Costalblue }+ \text { NIR2 }}
$$

\subsection{Bathymetry retrieval}

Depth retrieval in optical satellite imagery is based on the underlying concept of light absorption in water column. Green and blue light in particular have strong penetration in water. However, light penetration is constrained by water turbidity (light penetrates well in clear water). A major drawback comes from the presence of dark patches in the seafloor (e.g. patchwork of organism and substrates) which absorb more light indicating deeper water than it actually is. In this case, Karimun water is dominated by coral reef which implies that coral will virtually appear deeper than white sand in coastal waters. Previous studies have derived bathymetry from optical satellite imagery by using ratio of 
two spectral bands that is assumed to be constant for all bottom types (Mishra et al., 2007; Philpot, 1989).

In this present study, depth retrieval from Mishra et al. (2007) is adopted by using ratio band (green and blue) to form second-order polynomial function with in-situ depth. Two spectral bands with different water absorptions in water will also have different reflectance (one is with less value than the other) whereas bottom types influence both spectral bands similarly. Although green and blue region provide the strongest penetration in water, two newly added spectral bands of Worldview-3 (coastal blue and yellow) were also tested.

\section{Results and discussion}

\subsection{Atmospheric correction}

Atmospheric corrections (FLAASH and QUAC) were applied to atmospherically uncompensated Worldview-3 image to obtain surface reflectance ranging from 0 to 1 . On the other hand, AComp product was readily represented as surface reflectance in 11-bit, thus rescaling was done to retrieve surface reflectance that ranges from 0 to 1 . Three objects which included sand, mud and coral, were sampled in order to evaluate the performances of those three atmospheric correction models. Surface reflectance and Top-of-Atmosphere (ToA) reflectance were compared to see whether atmospheric corrections models had eliminated the atmospheric effects on the image.

As shown in Figure 4, AComp and FLAASH seemed to remove atmospheric effect quite well in which the TOA reflectance shows higher value than surface reflectance. AComp and FLAASH shared relatively the same pattern of surface reflectance from all three objects. On the contrary, QUAC appeared to be overestimating in its performance, indicated by higher surface reflectance than TOA reflectance of all three objects. Briefly, this result suggests that AComp and FLAASH have better performance than QUAC. Previous study on the comparison between AComp, FLAASH and QUAC has also reported that physics-based atmospheric correction model provides better results than the image-based atmospheric correction model (Smith, 2015).

\subsection{Band ratios evaluation}

Once the surface reflectance of water obtained from three atmospheric correction models was identified using NDWI, second-order polynomial function was built between surface reflectance and in-situ depth. Here, insitu depth data (depth $<20 \mathrm{~m})$ were sampled $(\mathrm{n}=360)$ in order to form polynomial function for bathymetry retrieval. In this study, four spectral bands of Worldview-3 of each atmospheric correction, namely coastal blue (B1), blue (B2), green (B3) and yellow (B4), were selected and combined to form band ratios. Table 1 shows the determination coefficient of band ratios of the selected spectral bands.

Table 1. The determination coefficient $\left(\mathrm{R}^{2}\right)$ of band ratios against in-situ depth

\begin{tabular}{|c|c|c|c|}
\hline Band Ratio & AComp & FLAASH & QUAC \\
\hline B1/B3 & 0.552 & 0.448 & 0.263 \\
\hline B2/B3 & 0.775 & 0.717 & 0.757 \\
\hline B1/B4 & 0.551 & 0.695 & 0.620 \\
\hline
\end{tabular}

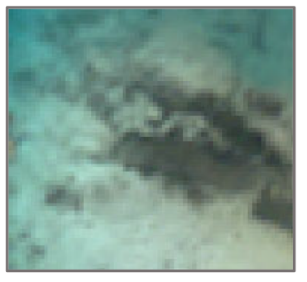

Coral

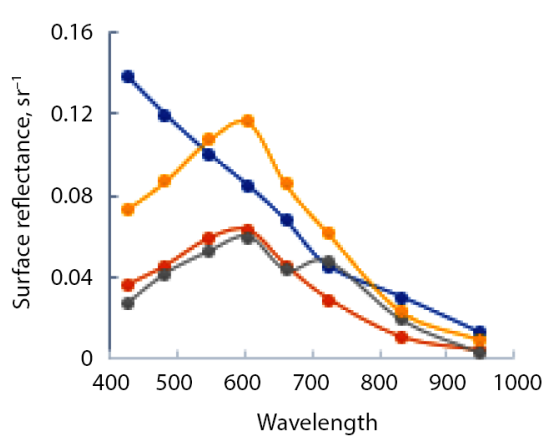

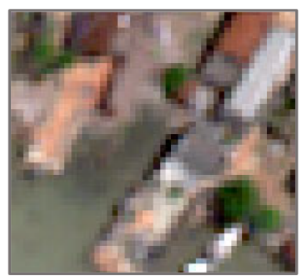

Mud

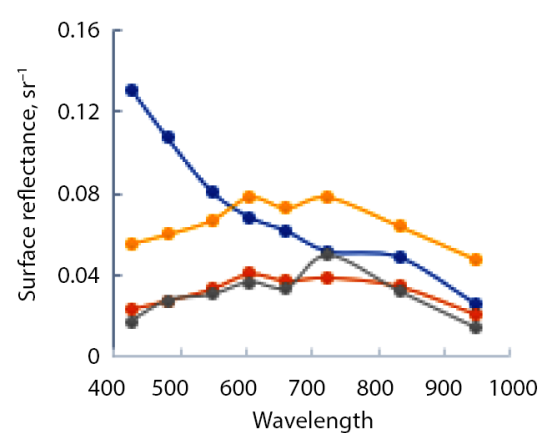

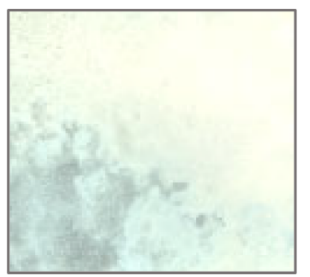

Sand

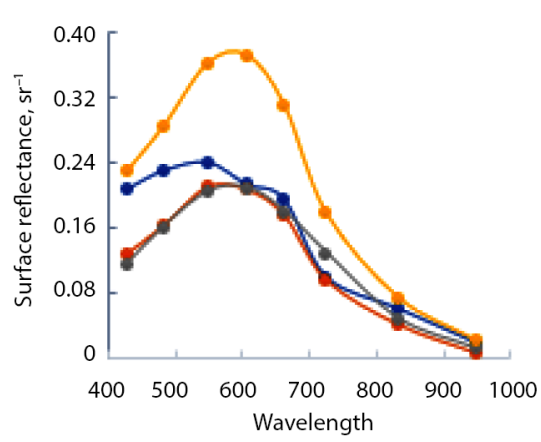

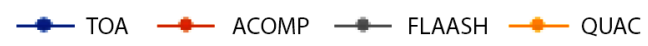

Figure 4. Comparison of TOA reflectance and surface reflectance obtained from three atmospheric correction models (AComp, FLAASH and QUAC) 
Based on this evaluation, the best performance was obtained by band ratio of blue and green band (B2/B3) from AComp product which explained $77.5 \%$ of the model (illustrated in Figure 5). Previous study reported that yellow band is effective for semi-analytical bathymetry retrieval (Nuha, 2019). Likewise, Parente and Pepe (2018) also stated that band ratio using yellow band provides the best performance for empirical bathymetry retrieval using Stumpf, Holderied and Sinclair (2003) method. However, there was no pattern found in this present evaluation which indicates that certain band ratio from one atmospheric correction model always corresponds to ether the highest or the smallest determination coefficient. Hence, we selected the blue and green band ratio which corresponds to the highest determination coefficient for bathymetry retrieval. This finding is also supported by Mishra et al. (2007) and Hernandez and Armstrong (2016) who also reported that blue and green band ratio provides the best performance.

\subsection{Bathymetry retrieval}

After selecting band ratio and establishing the model, depth was estimated based on the second-order polynomial function explaining the relationship between depth and band ratio. To evaluate the performance of bathymetry retrieval, we sampled 365 in-situ depth data (depth $<20 \mathrm{~m}$ ) to be further compared with estimated depth. Here, we presented the statistical assessment of the bathymetry retrieval in Table 2.

Table 2. Statistical evaluation of bathymetry retrieval in Karimun water

\begin{tabular}{|l|c|}
\hline \multicolumn{1}{|c|}{ Statistic } & Value \\
\hline$\Delta$ Minimum & $+0.001 \mathrm{~m}$ \\
\hline$\Delta$ Maximum & $+9.243 \mathrm{~m}$ \\
\hline$\Delta$ Average & $4.310 \mathrm{~m}$ \\
\hline$\Delta$ Root Mean Square Error & $2.076 \mathrm{~m}$ \\
\hline
\end{tabular}

Based on the statistical evaluation, the accuracy of estimated depth is $2.076 \mathrm{~m}$ in which the model overestimated depth up to $9.243 \mathrm{~m}$. The averaged-difference between insitu check depth with estimated depth is $4.310 \mathrm{~m}$. This result shows that even for bathymetry retrieval for depth $<20 \mathrm{~m}$, the model still failed to perform well with high overestimation. Figure 6 shows the bathymetry map obtained from Worldview-3 imagery in Karimun water.

Although the model did not really provide satisfactory result, the accuracy of estimated depth is relatively agreeable. Parente and Pepe (2018) performed their experiment with bathymetry retrieval on Worldview-3 imagery using Stumpf et al. (2003) method and obtained smaller accuracy which is $3.747 \mathrm{~m}$. On the other hand, by using LiDAR bathymetry, Hernandez and Armstrong (2016) has successfully performed bathymetry retrieval on Worldview-2 imagery using second-order polynomial method and obtained accurate SDB with RMSE of $1.56 \mathrm{~m}$. These previous studies along with this present work suggest that bathymetry retrieval on high-resolution multispectral imagery can be robust alternative method for deriving bathymetry in shallow waters in which suitable atmospheric correction model and bathymetry retrieval algorithm are required to produce bathymetry map with decent accuracy.

\section{Conclusions}

High-resolution multispectral imagery has made significant contribution in marine studies. With the advances of remote sensing satellites, scientists have gained tremendous opportunity to study and retrieve bathymetry map using improved spectral and spatial resolution imagery such as Worldview-3. In this study, an evaluation has been presented in comparing three atmospheric correction models (i.e. AComp, FLAASH and QUAC) on Worldview-3 imagery for bathymetry retrieval. Here, AComp provides the best performance compared to the two competitors. In our case, bathymetry retrieval was

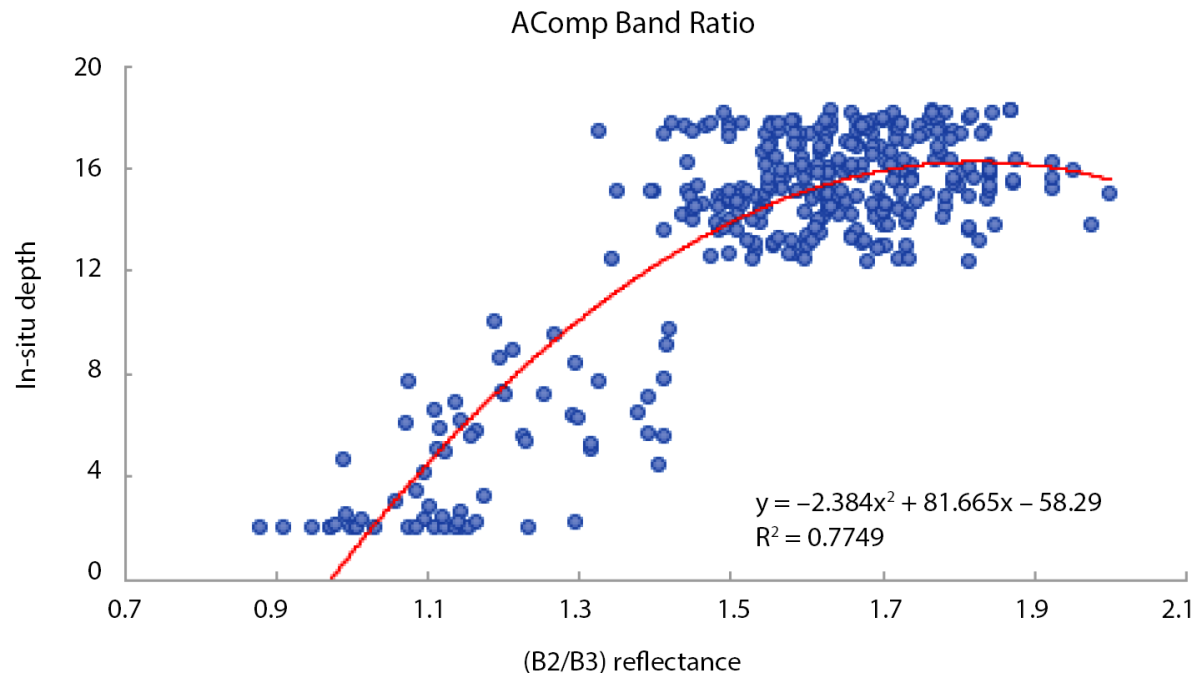

Figure 5. Second-order polynomial model of blue and green band ratio from AComp product 


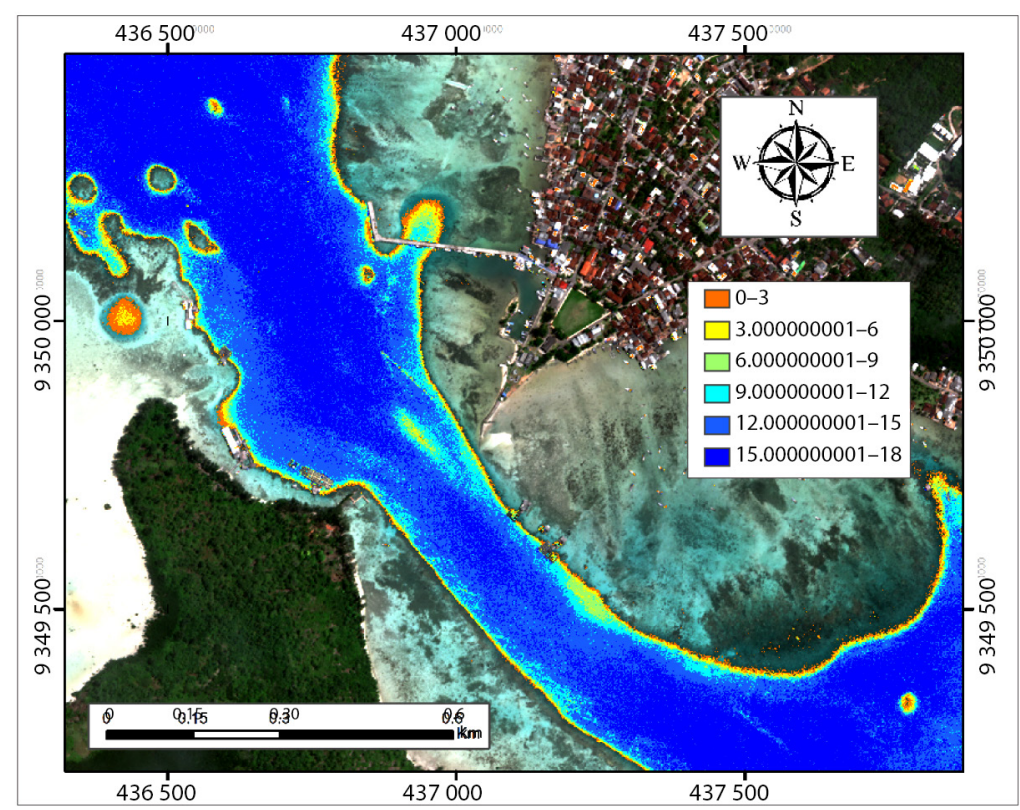

Figure 6. Bathymetry map retrieved from Worldview-3 in Karimun water

performed using blue and green band ratio by which it corresponds to the highest determination coefficient $\left(\mathrm{R}^{2}=0.7749\right)$ against in-situ depth measured by single beam echosounder. By using blue and green band ratio, bathymetry was successfully retrieved based on secondorder polynomial model with the accuracy of $2.076 \mathrm{~m}$ when compared to in-situ depth. In conclusion, highresolution multispectral imagery is robust alternative method for deriving bathymetry provided that the atmospheric effects on the image have been removed and suitable SDB algorithm is employed.

\section{Acknowledgements}

This work is supported by Department of Geodetic Engineering, Universitas Gadjah Mada and carried out within the framework of Research and Community Service (Penelitian dan Pengabdian Masyarakat, PPM) project. Authors also thank Remote Sensing Application Centre, National Institute of Aeronautics and Space for all extensive contributions for this work.

\section{Funding}

This work was supported by Department of Geodesy, Universitas Gadjah Mada, under Grant Number 231.j/H1.17/ TGD/PL/2019.

\section{Author contributions}

Abdul Basith was responsible for data acquisition and design of data analysis. In addition, Ratna Prastyani was responsible for data processing and data analysis.

\section{References}

Bernstein, L. S., Adler-golden, S. M., Jin, X., Gregor, B., \& Sundberg, R. L. (2012a). Quick atmospheric correction (QUAC) code for VNIR-SWIR spectral imagery: Algorithm details. In 4th Workshop on Hyperspectral Image and Signal Processing (WHISPERS). IEEE.

https://doi.org/10.1109/WHISPERS.2012.6874311

Bernstein, L. S., Jin, X., Gregor, B., \& Adler-Golden, S. M. (2012b). Quick atmospheric correction code: algorithm description and recent upgrades. Optical Engineering, 51(11), 111719. https://doi.org/10.1117/1.oe.51.11.111719

Cooley, T., Anderson, G. P., Felde, G. W., Hoke, M. L., Ratkowski, A. J., Chetwynd, J. H., Gardner, J. A., Adler-Golden, S. M., Matthew, M. W., Berk, A., Bernstein, L. S., Acharya, P. K., Miller, D., \& Lewis, P. (2002). FLAASH, a MODTRAN4based atmospheric correction algorithm, its applications and validation. International Geoscience and Remote Sensing Symposium (IGARSS), (pp. 1414-1418). IEEE.

https://doi.org/10.1109/IGARSS.2002.1026134

Delegido, J., Verrelst, J., Alonso, L., \& Moreno, J. (2011). Evaluation of sentinel-2 red-edge bands for empirical estimation of green LAI and chlorophyll content. Sensors, 11(7), 70637081. https://doi.org/10.3390/s110707063

Digital Globe. (2010). The Benefits of the eight spectral bands of Worldview-2 (pp. 1-12). https://dg-cms-uploads-production. s3.amazonaws.com/uploads/document/file/35/DG-8SPECTRAL-WP_0.pdf

Eugenio, F., Marcello, J., Martin, J., \& Rodríguez-Esparragón, D. (2017). Benthic habitat mapping using multispectral highresolution imagery: Evaluation of shallow water atmospheric correction techniques. Sensors, 17(11), 2639.

https://doi.org/10.3390/s17112639

Giardino, C., Brando, V. E., Gege, P., Pinnel, N., Hochberg, E., Knaeps, E., Reusen, I., Doerffer, R., Bresciani, M., Braga, F., Foerster, S., Champollion, N., \& Dekker, A. (2019). Imaging 
spectrometry of Inland and Coastal waters: State of the art, achievements and perspectives. Surveys in Geophysics, 40(3), 401-429. https://doi.org/10.1007/s10712-018-9476-0

Harris Geospatial. (2009). Atmospheric correction module: QUAC and FLAASH User' s guide. Atmospheric Correction Module: QUAC and FLAASH User's Guide (pp. 20-21).

https://www.harrisgeospatial.com/portals/0/pdfs/envi/ Flaash_Module.pdf

Hell, B., Broman, B., Jakobsson, L., Jakobsson, M., Magnusson, A., \& Wiberg, P. (2012). The use of bathymetric data in society and science: A review from the Baltic Sea. Ambio, 41(2), 138-150. https://doi.org/10.1007/s13280-011-0192-y

Hernandez, W. J., \& Armstrong, R. A. (2016). Deriving bathymetry from multispectral remote sensing data. Journal of Marine Science and Engineering, 4(1), 8. https://doi.org/10.3390/jmse4010008

Ilori, C. O., Pahlevan, N., \& Knudby, A. (2019). Analyzing performances of different atmospheric correction techniques for Landsat 8: Application for coastal remote sensing. Remote Sensing, 11(4), 1-20. https://doi.org/10.3390/rs11040469

Jawak, S. D., Vadlamani, S. S., \& Luis, A. J. (2015). A synoptic review on deriving bathymetry information using remote sensing technologies: Models, methods and comparisons. Advances in Remote Sensing, 4(2), 147-162. https://doi.org/10.4236/ars.2015.42013

Kotchenova, S. Y., \& Vermote, E. F. (2007). Validation of a vector version of the $6 \mathrm{~S}$ radiative transfer code for atmospheric correction of satellite data. Part II. Homogeneous Lambertian and anisotropic surfaces. Applied Optics, 46(20), 4455-4464. https://doi.org/10.1364/AO.46.004455

Liang, S., Li, X., \& Wang, J. (Eds.). (2012). Atmospheric correction of optical imagery. In Advanced Remote Sensing (p. 117). https://doi.org/10.1016/B978-0-12-385954-9.00005-8

Lyzenga, D. R. (1981). Remote sensing of bottom reflectance and water attenuation parameters in shallow water using aircraft and landsat data. International Journal of Remote Sensing, 2(1), 71-82. https://doi.org/10.1080/01431168108948342

Lyzenga, D. R., Malinas, N. P., \& Tanis, F. J. (2006). Multispectral bathymetry using a simple physically based algorithm. IEEE Transactions on Geoscience and Remote Sensing, 44(8), 2251-2259. https://doi.org/10.1109/TGRS.2006.872909

Mavraeidopoulos, A., Pallikaris, A., \& Oikonomou, E. (2018). Satellite Derived Bathymetry (SDB) and safety of navigation. The International Hydrographic Review, (17), 7-19.

McFeeters, S. K. (1996). The use of the Normalized Difference Water Index (NDWI) in the delineation of open water features. International Journal of Remote Sensing, 17(7), 14251432. https://doi.org/10.1080/01431169608948714
Mishra, D. R., Narumalani, S., Rundquist, D., Lawson, M., \& Perk, R. (2007). Enhancing the detection and classification of coral reef and associated benthic habitats: A hyperspectral remote sensing approach. Journal of Geophysical Research: Oceans, 112(8), 1-18. https://doi.org/10.1029/2006JC003892

Nuha, M. U. (2019). Optimization of analytical parameters to derive bathymetry with high resolution satellite imagery on shallow water. Univeristas Gadjah Mada.

Parente, C., \& Pepe, M. (2018). Bathymetry from worldview-3 satellite data using radiometric band ratio. Acta Polytechnica, 58(2), 109-117. https://doi.org/10.14311/AP.2018.58.0109

Philpot, W. D. (1989). Bathymetric mapping with passive multispectral imagery. Applied Optics, 28(8), 1569. https://doi.org/10.1364/ao.28.001569

Richter, R., \& Schläpfer, D. (2002). Geo-atmospheric processing of airborne imaging spectrometry data. Part 2: Atmospheric/ topographic correction. International Journal of Remote Sensing, 23(13), 2631-2649. https://doi.org/10.1080/01431160110115834

Said, N. M., Mahmud, M. R., \& Hasan, R. C. (2017). Satellitederived bathymetry: Accuracy assessment on depths. The International Archives of the Photogrammetry, Remote Sensing and Spatial Information Sciences, XLII(October), 159-164. https://doi.org/10.5194/isprs-archives-XLII-4-W5-159-2017

Sánchez-Carnero, N., Ojeda-Zujar, J., Rodríguez-Pérez, D., \& Marquez-Perez, J. (2014). Assessment of different models for bathymetry calculation using SPOT multispectral images in a high-turbidity area: The mouth of the Guadiana Estuary. International Journal of Remote Sensing, 35(2), 493-514. https://doi.org/10.1080/01431161.2013.871402

Shi, L., Mao, Z., \& Wang, Z. (2018). Retrieval of total suspended matter concentrations from high resolution WorldView-2 imagery: A case study of inland rivers. IOP Conference Series: Earth and Environmental Science, 121(3), 032036. https://doi.org/10.1088/1755-1315/121/3/032036

Smith, M. J. (2015). A comparison of DG AComp, FLAASH and QUAC atmospheric compensation algorithms using WorldView-2 IMagery. https://digitalglobe-marketing. s3.amazonaws.com/files/blog/MichaelSmith_Masters_Report_ACOMP_Assessment.pdf

Stumpf, R. P., Holderied, K., \& Sinclair, M. (2003). Determination of water depth with high-resolution satellite imagery over variable bottom types. Limnology and Oceanography, 48(1 II), 547-556. https://doi.org/10.4319/lo.2003.48.1_part_2.0547

Vanhellemont, Q., \& Ruddick, K. (2016). Acolite for Sentinel-2: Aquatic applications of MSI imagery. ESA Special Publication SP-740, 9-13. http://odnature.naturalsciences.be/downloads/ publications/2016_Vanhellemont_ESALP.pdf 